\title{
An overview on the nutrition transition and its health implications: the Bellagio meeting
}

\section{Introduction}

This supplement is based on papers presented at the Bellagio Conference on the Nutrition Transition. The meeting was organised to allow us to assess current lowand moderate-income industrialising countries' experience related to the nutrition transition and provide ideas for pushing forth a broader public health agenda in this area. More specifically, the meeting focused on changes in patterns of behaviour (diet, smoking, drinking, activity) that lead to rapid increases in obesity, cardiovascular disease (CVD) and cancer. The nutrition-related noncommunicable diseases (NR-NCDs) were once referred to as diseases of affluence. For decades this has not been true among higher-income countries, and as we now show, this is increasingly not the case in the lower- and middleincome countries.

Two historic processes of change occur simultaneous to or precede the nutrition transition. One is the demographic transition - the shift from a pattern of high fertility and high mortality to one of low fertility and low mortality (typical of modern industrialised countries). Even more directly relevant is the epidemiological transition, first described by Omran ${ }^{1}$ : the shift from a pattern of high prevalence of infectious diseases associated with malnutrition, and periodic famine and poor environmental sanitation, to a pattern of high prevalence of chronic and degenerative diseases associated with urban-industrial lifestyles. A third pattern of delayed degenerative diseases has been formulated more recently (e.g. Olshansky and Ault ${ }^{2}$ ). Accompanying this progression is a major shift in age-specific mortality patterns and a consequent increase in life expectancy. Interpretations of the demographic and epidemiological transitions share a focus with the nutrition transition on the ways in which populations move from one pattern to the next.

Similarly, large shifts have occurred in dietary and physical activity and inactivity patterns. These changes are reflected in nutritional outcomes, such as changes in average stature and body composition. Modern societies seem to be converging on a pattern of diet high in saturated fat, sugar and refined foods and low in fibre often termed the 'Western diet'. Many see this dietary pattern to be associated with high levels of chronic and degenerative diseases and with reduced disability-free time. These three relationships are presented in Fig. 1.

Human diet and activity patterns and nutritional status have undergone a sequence of major shifts, defined as broad patterns of food use and their corresponding nutrition-related diseases. Over the last three centuries, the pace of dietary and activity change appears to have accelerated, to varying degrees in different regions of the world. Further, dietary and activity changes are paralleled by major changes in health status, as well as by major demographic and socio-economic changes. Obesity emerges early in these shifting conditions as does the level and age composition of morbidity and mortality. We can think of five broad nutrition patterns. They are not restricted to particular periods of human history. For convenience, the patterns are outlined as historical developments; however, 'earlier' patterns are not restricted to the periods in which they first arose but continue to characterise certain geographic and socioeconomic sub-populations.

\section{Pattern 1: Collecting Food}

This diet, which characterises hunter-gatherer populations, is high in carbohydrates and fibre and low in fat, especially saturated $\mathrm{fat}^{3,4}$. The proportion of polyunsaturated fat in meat from wild animals is significantly higher than in meat from modern domesticated animals ${ }^{5}$. Activity patterns are very high and little obesity is found among hunter-gatherer societies. It is important to note that much of the research on hunter-gatherers is based on modern hunter-gatherers as there is much less evidence on pre-historic people.

\section{Pattern 2: Famine}

The diet becomes much less varied and subject to larger variations and periods of acute scarcity of food. These dietary changes are hypothesised to be associated with nutritional stress and a reduction in stature (estimated by some at about 4 inches $^{6,7}$ ). During the later phases of this pattern, social stratification intensifies, and dietary variation increases according to gender and social status ${ }^{8}$. The pattern of famine (as with each of the patterns) has varied over time and space. Some civilisations are more successful than others in alleviating famine and chronic hunger, at least for their more privileged citizens ${ }^{9}$. The types of physical activity changed but there was little change in activity levels during this period.

\section{Pattern 3: Receding Famine}

The consumption of fruit, vegetables and animal protein increases, and starchy staples become less important in the diet. Many earlier civilisations made great progress in reducing chronic hunger and famines, but only in the last third of the last millennium have these changes become widespread, leading to marked shifts in diet. However, famines continued well into the eighteenth century in 
Demographic Transition

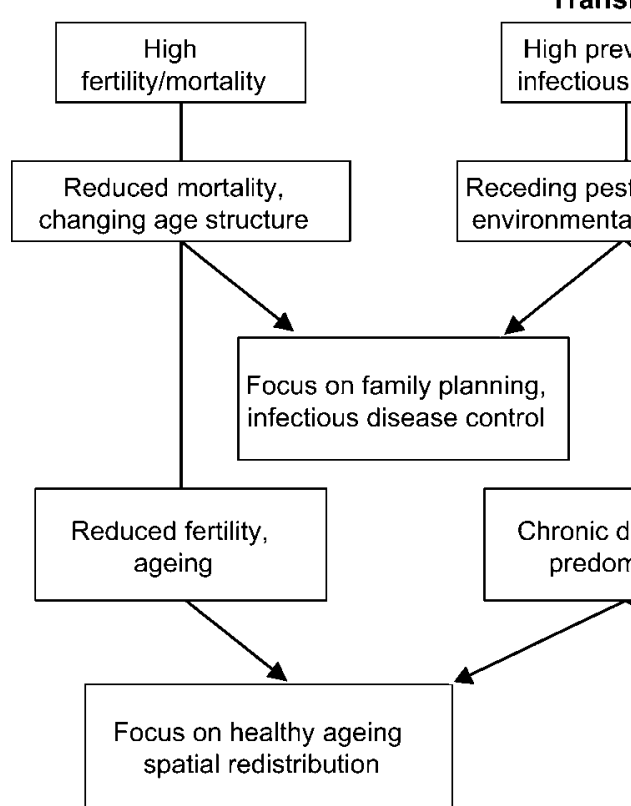

Overview of the nutrition transition and its health implications

\section{Nutrition Transition}

Transition

igh prevalence

ectious disease

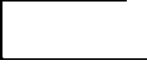

conditions

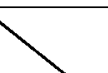

\section{High prevalence \\ undernutrition}

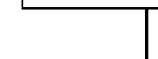

Receding famine
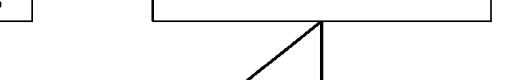

Focus on famine alleviation/prevention
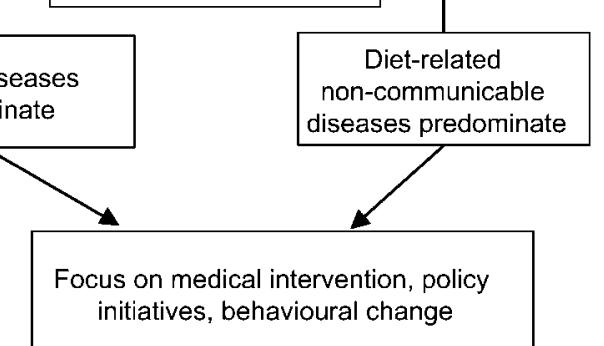

Fig. 1 Stages of health, nutritional and demographic change

portions of Europe and remain common in some regions of the world. Activity patterns start to shift and inactivity and leisure become part of the lives of more people.

\section{Pattern 4: Nutrition-related Non-communicable Disease}

A diet high in total fat, cholesterol, sugar and other refined carbohydrates, and low in polyunsaturated fatty acids and fibre, and often accompanied by an increasingly sedentary life, is characteristic of most high-income societies (and of increasing portions of the population in low-income societies). This results in increased prevalence of obesity and contributes to the degenerative diseases that characterise Omran's final epidemiological stage.

\section{Pattern 5: Bebavioural Change}

A new dietary pattern appears to be emerging as a result of changes in diet, evidently associated with the desire to prevent or delay degenerative diseases and prolong health. Whether these changes, instituted in some countries by consumers and in others also prodded by government policy, will constitute a large-scale transition in dietary structure and body composition remains to be $\operatorname{seen}^{10-12}$. If such a new dietary pattern takes hold, it may be very important in enhancing 'successful ageing'; that is, postponing infirmity and increasing the disability-free life expectancy ${ }^{13,14}$.

Our focus is increasingly on patterns 3 to 5 , in particular on the rapid shift in many of the world's low- and moderate-income countries from the stage of receding famine to NR-NCD. Figure 2 presents this focus. The concern about this period is so great that the term the Nutrition Transition is synonymous, for many, with this shift from Pattern 3 to 4 .

In the conference and this journal supplement, the papers are arranged around several themes. We present these and note the key issues in each paper.

What has happened in terms of some of the unique elements of shift in diet, activity, obesity, and other measures of morbidity and mortality within different regions of the world?

Many of the papers were country studies that capture the key trends in diet, physical activity, body composition and NR-NCD that could be measured on a large-scale basis. Data are very scarce in many countries, in particular for diet and physical activity, so the main common denominator is data on overweight and obesity. Overall we know that four-fifths of the world's burden of NR-NCD comes from the low- and moderate-income countries. These papers provide some insights into ways that the key nutritional risk factors have changed.

\section{Latin America}

Many countries in this region began their transition earlier in the past century and certainly entered the NR-NCD stage far earlier than did other regions. But there is enormous heterogeneity and countries such as Haiti and subpopulations in Central America are still in the receding famine period. Moreover, some such as Mexico really experienced an accelerated transition in the 1990s.

The case studies are important for showing that the 


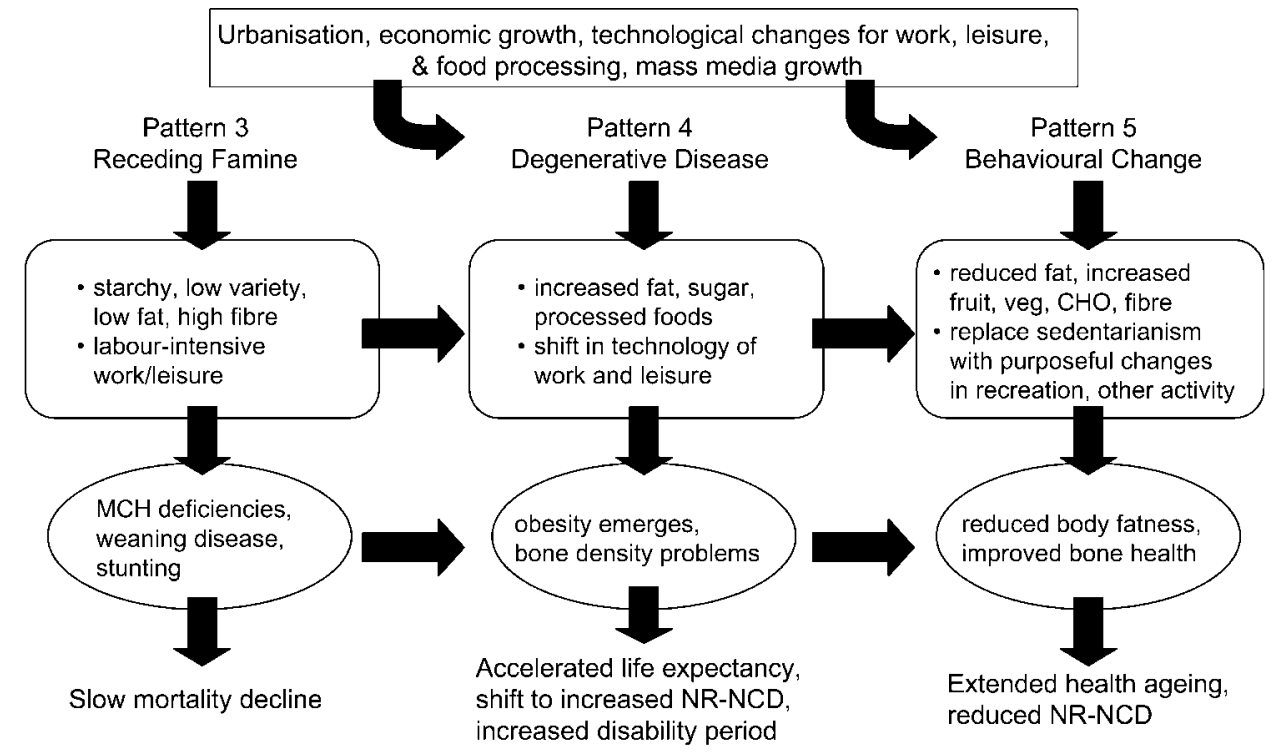

Fig. 2 Stages of the nutrition transition

burden of disease has shifted towards the poor for selected sub-populations in this region. Brazil and Chile, in particular, were the first to reach this stage. In the case of Chile, as noted by Albala et al. ${ }^{15}$, the largest burden of obesity has already been placed on the poor. Monteiro et $a{ }^{16}{ }^{6}$ show how rapidly obesity has replaced undernutrition in Brazil and the way the shift in obesity towards a burden for the poor is occurring for Brazilian women but not yet for the men. The paper by Albala et al. ${ }^{15}$ also describes the burden of disease related to obesity in Chile.

As Rivera et ll $^{17}$ show, Mexico exhibits a later shift than the other Latin American countries presented; however, in a very short period of time it has seen marked increases in obesity and has displayed a pattern of change where the prevalence of adult-onset diabetes emerges as very high.
In Mexico over $7 \%$ of adults are diabetic. Obesity levels are very high, almost as high as those observed among Mexican-Americans residing in the USA. In the US, with its very high level of obesity, diabetes affects $8 \%$ of the population aged 20 years and older.

The Cuba case study is important for showing how large-scale macroeconomic changes, in this case caused by exogenous forces linked with the cessation of subsidies from the Soviet Union and other causes, can affect energy imbalance and obesity in a positive manner and can rapidly alter the health of the population. At the same time there were adverse effects on nutritional status not addressed in this paper. The shortage of imported fuel and foods was linked with a marked shift in total energy and the proportion of energy from fat. At the same time physical activity increased and the net effect was a

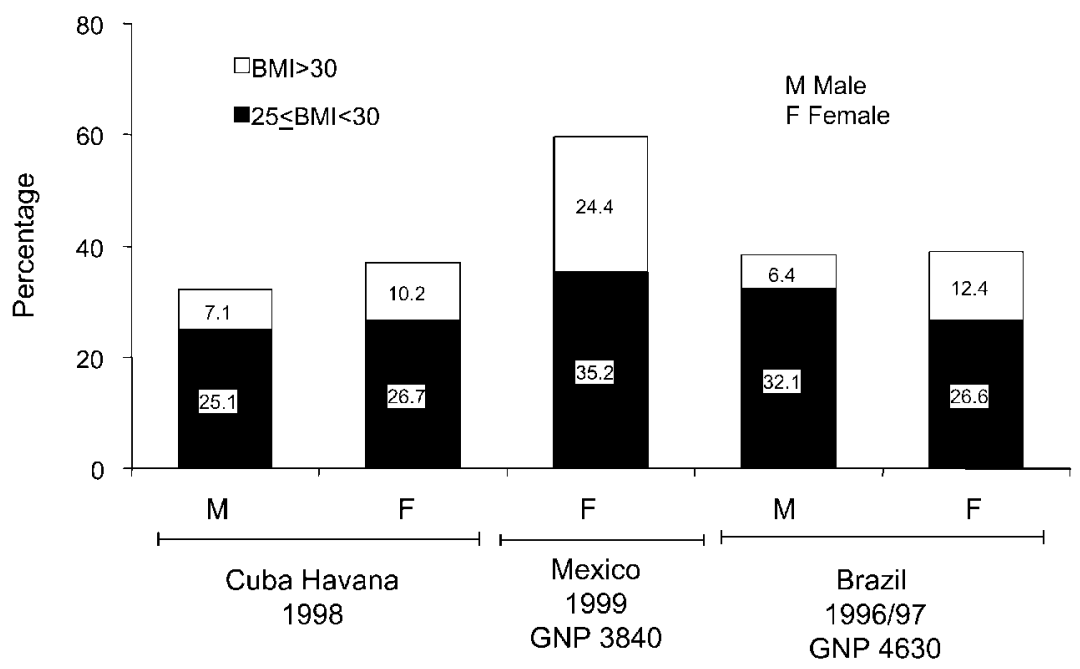

Fig. 3 Obesity patterns among adults in Latin America. GNP - per capita gross national product (in 1998 US\$). Sources: Monteiro et al. ${ }^{16}$, Rivera et al. ${ }^{17}$ and Rodríguez-Ojea et al. ${ }^{18}$ 


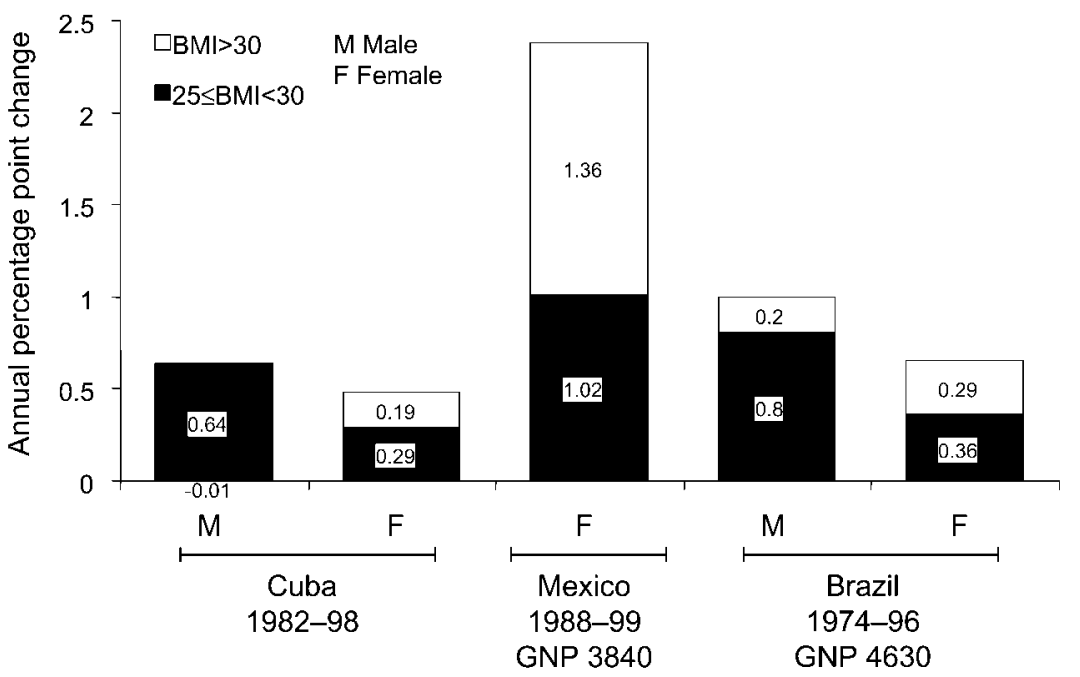

Fig. 4 Obesity trends among adults in Latin America (the annual percentage point increase in prevalence). GNP - per capita gross national product (in 1998 US\$). Sources: Monteiro et al. ${ }^{16}$, Rivera et al. ${ }^{17}$ and Rodríguez-Ojea et al. ${ }^{18}$

reduced prevalence of obesity. There were not, unfortunately, the types of monitoring survey that allowed one to understand the health effects of this change in the prevalence of obesity.

Figures 3 and 4 present data from these papers on obesity $^{16-18}$. Figure 4 shows how quickly overweight and obesity status have emerged in Mexico as a major public health problem. In Fig. 3 we present the most recent data on overweight and obesity for males and females. Figure 4 presents the annualised increase in the percentage points of prevalence for data from countries with comparable data. Compared with the USA and European countries, where the annual prevalence increase in overweight and obesity are about 0.25 each, respectively, the rates of change are very high in Latin America. Cuba's data represent Havana only.

The dietary shifts for this region also are quite different from those experienced by the other regions. The South American countries underwent a shift towards a diet high in animal products long ago. Their fat intake comes more from saturated fat sources. Also, added sugar intake is higher in the region. By comparison, in Mexico, the shift in

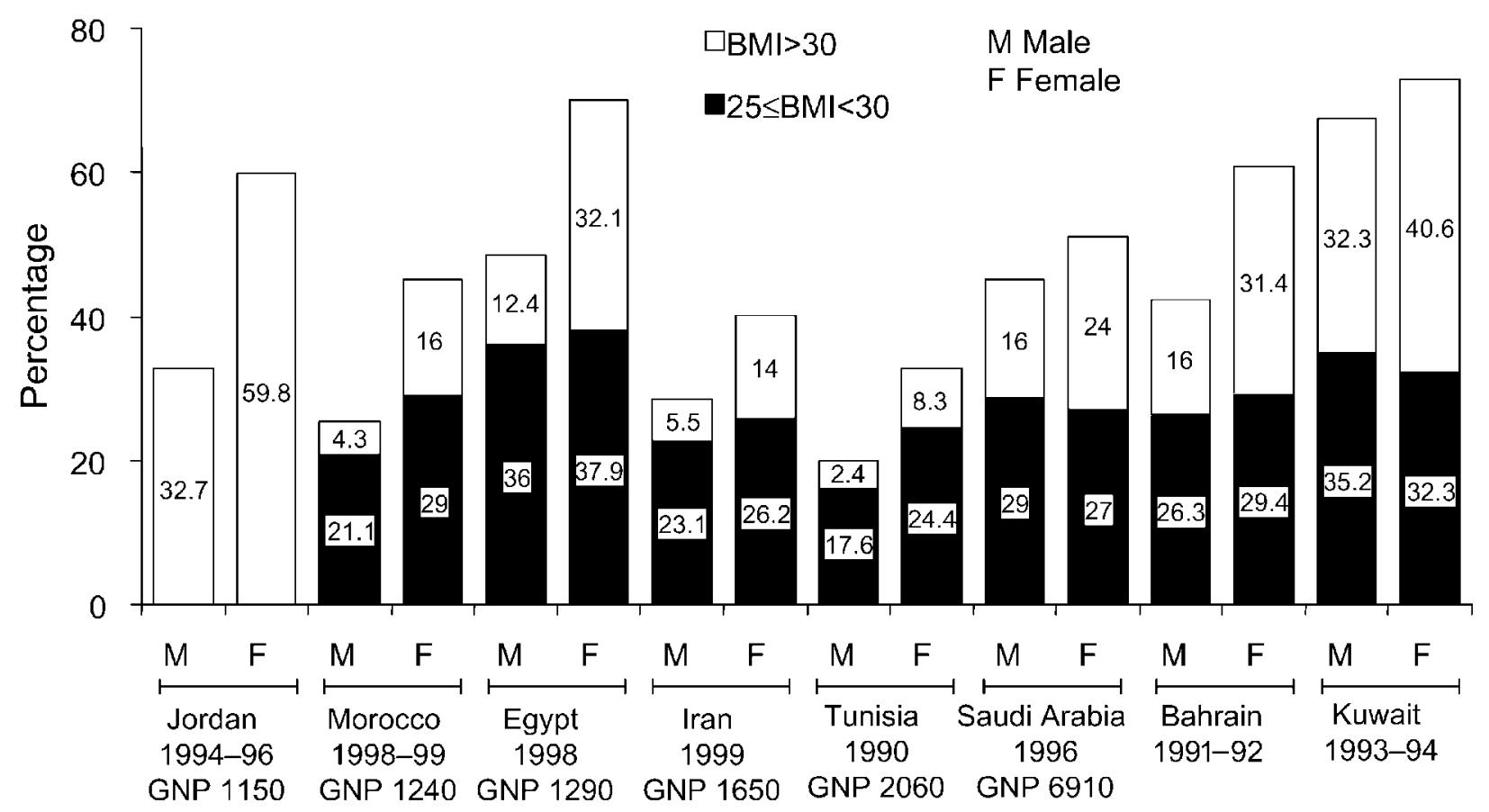

Fig. 5 Obesity patterns among adults in North Africa/Middle East. GNP - per capita gross national product (in 1998 US\$). Sources: Galal $^{19}$, Benjelloun ${ }^{20}$, Ghassemi et al. ${ }^{21}$, Al-Isa ${ }^{22,23}$, Al-Nuaim et al. ${ }^{24}$, Al-Mannai ${ }^{25}$, Shetty ${ }^{26}$ and Ajlouni et al. ${ }^{27}$ 
structure of the diet is dominated by a reduction in cereal products and tortillas with less clarity in the types of foods that have replaced these items.

\section{North Africa/Middle East}

This region does not possess the depth and quality of historical data on diet, activity and body composition that allows for a clear assessment of the timing of the shift in the nutrition transition stage. In fact, there are so few systematic data on dietary trends that it is not possible to get a sense of the role of either shifts in the structure and level of dietary intake or physical activity and inactivity in the current high levels of obesity and NR-NCDs. All of the authors discussed the possibility that a culture based on a desire for a larger body size and less activity may be important, but again this topic has not been studied.

Galal's paper ${ }^{19}$ on Egypt provides evidence of a very high level of overweight and obesity in Egypt, but this paper provides no sense of when obesity emerged as a public health problem in Egypt. Egypt suffers from very high rates of hypertension, diabetes and other obesity comorbidities. Women are more likely to be obese but the prevalence among men is also very high (overweight and obesity affect about two-thirds of urban and one-third of rural men, and over $80 \%$ of urban and $56 \%$ of rural women).

Benjelloun ${ }^{20}$ documents a similar very rapid increase in obesity and a shift towards an energy-dense diet in Morocco. Although the association with education is inverse, income is still positively associated with obesity in
Morocco. Females are disproportionately affected, but obesity is also a major problem among men.

Ghassemi et al. ${ }^{21}$ show that, despite a lack of sustained economic growth, over-consumption of a less energydense diet is linked with obesity, in particular in the urban areas. Even in rural areas, over a quarter of adults (men and women) are overweight or obese, while in urban areas the rates are higher. Overall, more than 28\% of Iranian men and 40\% of women are overweight or obese. Diabetes and other obesity co-morbidities are becoming significant public health problems.

We summarise the patterns and trends of overweight and obesity in this region in Figs $5^{19-27}$ and $6^{20,22,28}$. Trend data are available for only a few countries in the region.

\section{Sub-Sabaran Africa}

This is the poorest region in the world. Marked by political and economic instability and great variations in natural resources, many of the poorest countries in the world reside in this region. Again, there are no systematic national surveys that have obtained dietary and activity data and only minimal data on dietary trends, but there are some good obesity and NR-NCD morbidity and mortality data (Fig. 7) 26,28,29. Yet even among the poorest, large proportions of the population are shifting towards the NRNCD patterns found in other regions of the low- and moderate-income world. At the same time the region faces the scourge of HIV/AIDS in a very intense manner. The critical question posed by the papers presented here is: for those adults who survive HIV/AIDS, will they have a

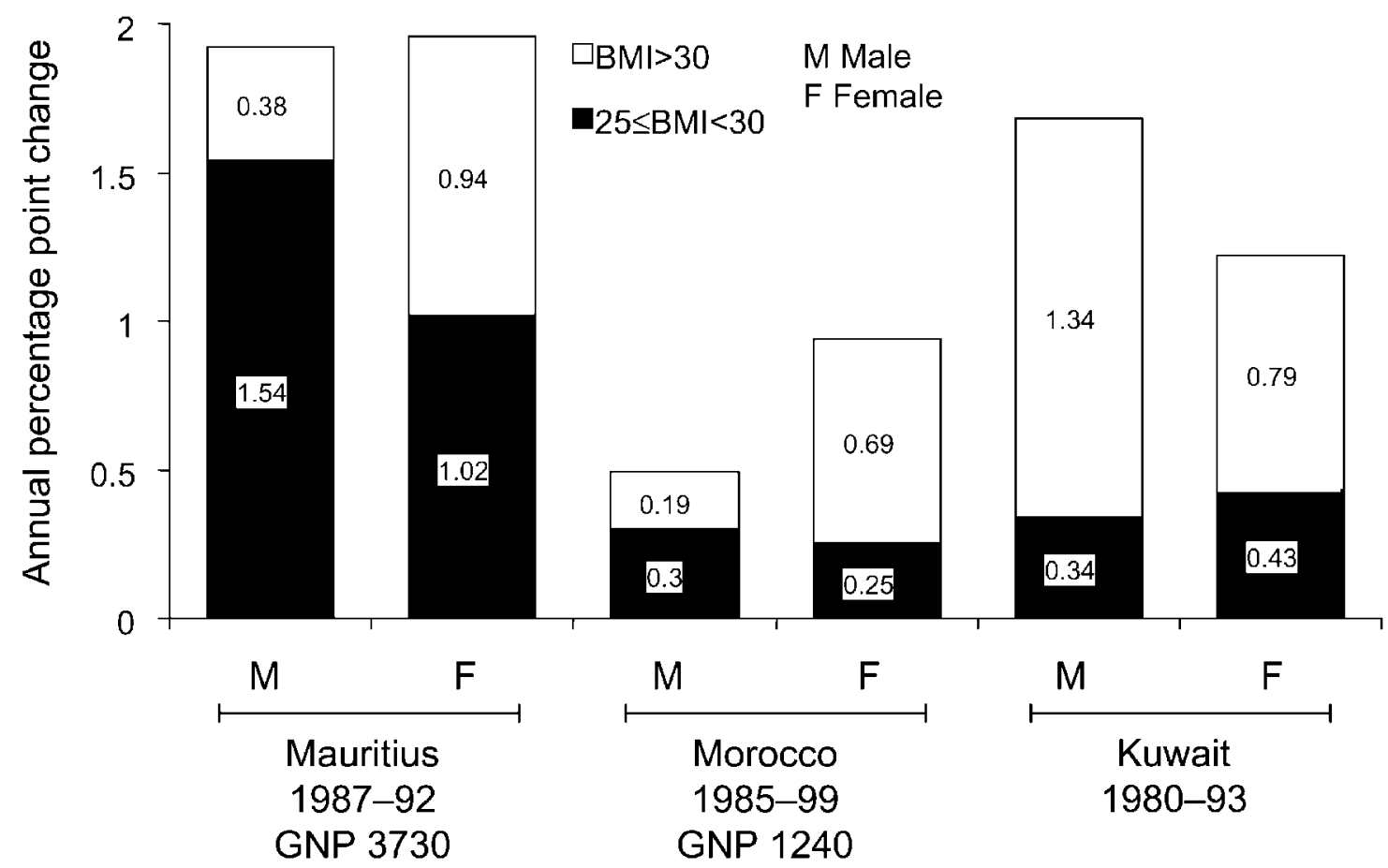

Fig. 6 Obesity trends among adults in North Africa/Middle East (the annual percentage point increase in prevalence). GNP - per capita gross national product (in 1998 US\$). Sources: Benjelloun ${ }^{20}$, Al-Isa $^{22,23}$ and Hodge et al. ${ }^{28}$ 


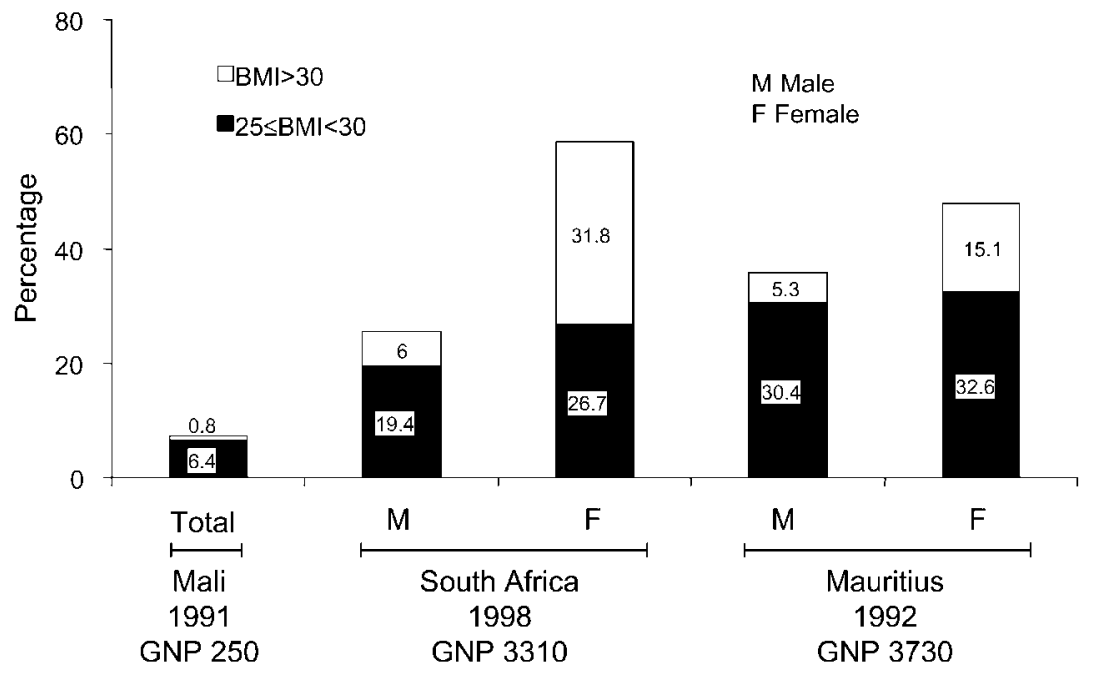

Fig. 7 Obesity patterns among adults in sub-Saharan Africa. GNP - per capita gross national product (in 1998 US\$). Sources: Shetty ${ }^{26}$, Hodge et al. ${ }^{28}$ and Bourne et al. ${ }^{29}$

burden of disease linked with high levels of NR-NCDs and will this burden affect their capacity to care for the future generation of adults?

Bourne et al.'s paper ${ }^{29}$ provides a convincing picture of a lifestyle that has led to very high levels of obesity and overweight among black South Africans (Fig. 7). There has been a marked increase in the fat density of their diet and also in the proportion of adults, in particular women, who are overweight or obese (close to 60\%). Over a quarter of men fit this same category and close to a quarter of the population is hypertensive. Bourne has also presented data (not in her paper) that reflect the large changes in the age composition of South Africa that will occur over the next two decades as the full impact of the HIV/AIDS epidemic is felt.

Tanzania, one of the poorest countries in sub-Saharan Africa, faces similar problems although in a more limited manner ${ }^{30}$. Diabetes and hypertension are clearly diseases of the affluent still, but as we show in Fig. 8 with Demographic and Health Survey (DHS) data, obesity is a problem among all groups in Tanzania. DHS covers women of childbearing age with pre-school children, a very young sample, and collected weight and height data for many sub-Saharan African countries in a comparable manner. Obesity is increasing and over 13\% of the sampled women were overweight or obese in Tanzania.

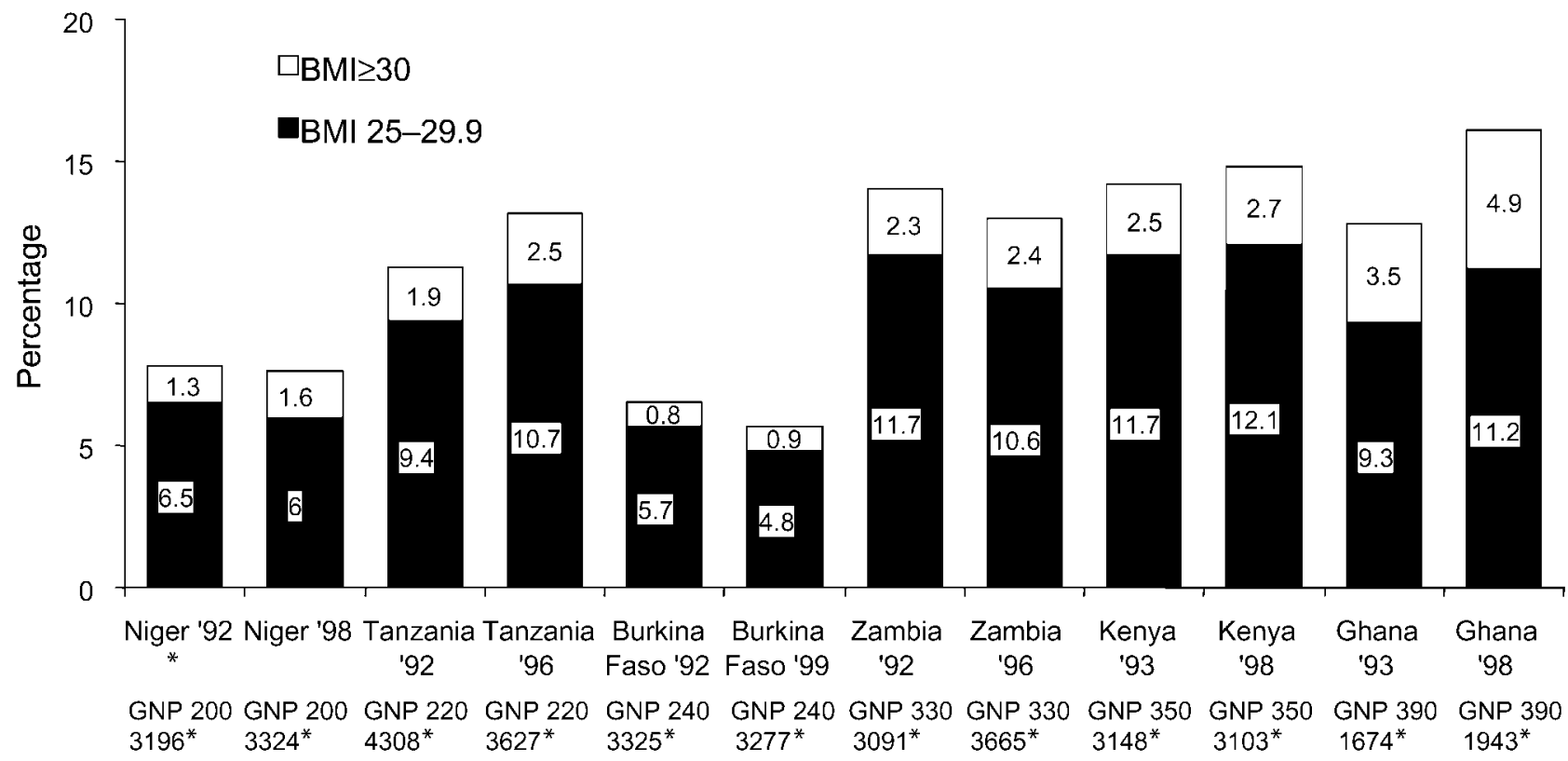

Fig. 8 DHS trends for females in sub-Saharan Africa. GNP - per capita gross national product (in 1998 US\$). *, Sample size 


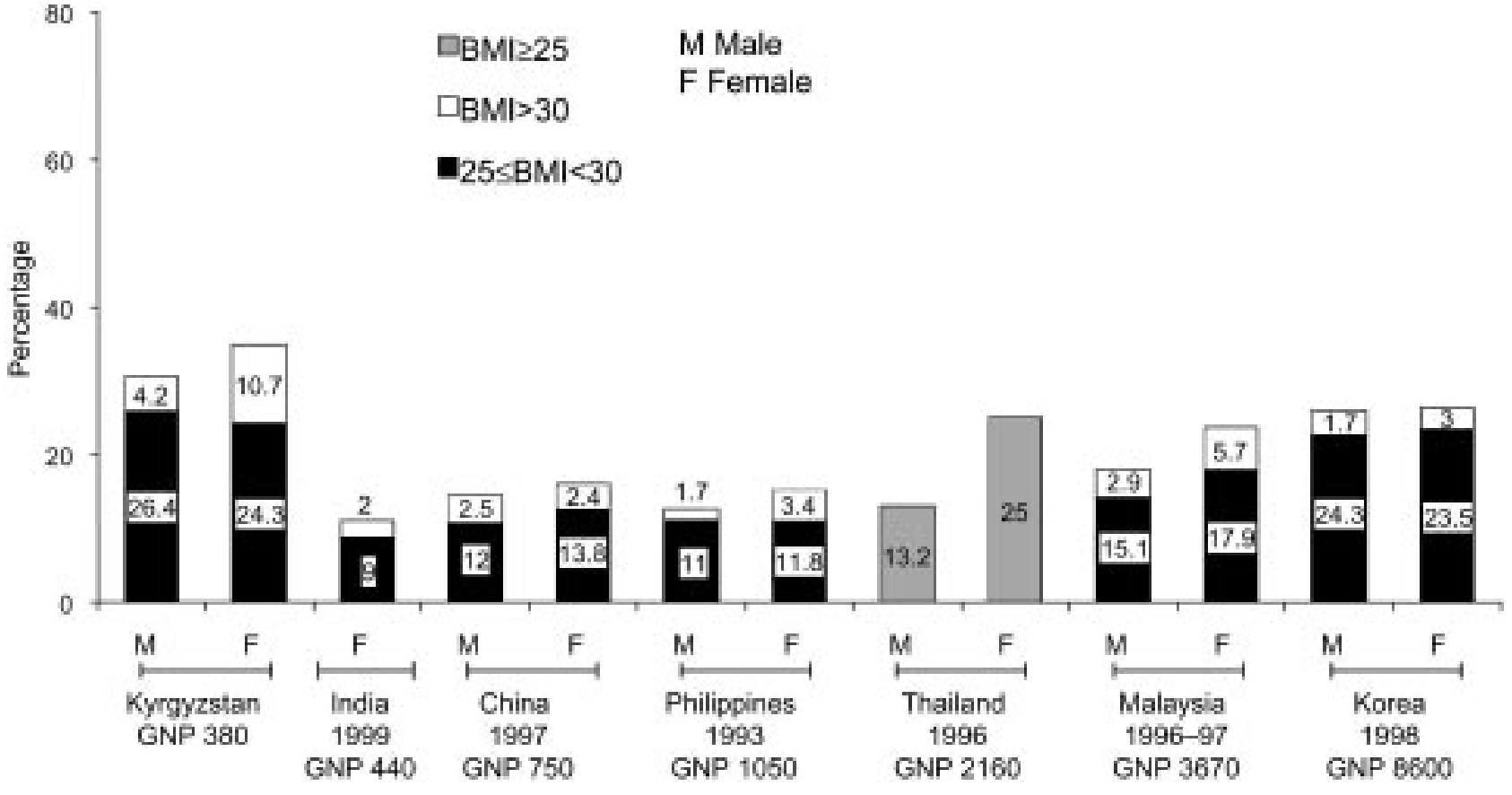

Fig. 9 Obesity patterns among adults in Asia. GNP - per capita gross national product (in 1998 US\$). Sources: Du et al. ${ }^{31}$, Kosulwat ${ }^{32}$, Noor ${ }^{33}$, Lee et al. $^{34}$; Shetty ${ }^{35}$, Solon ${ }^{36}$ and Popkin et al. ${ }^{37}$

\section{Asia}

Better dietary data are found in this region and even good activity data for China. Thus it has been possible to document, in papers presented here and elsewhere, that the period 1985-2000 saw one of the great shifts in dietary and physical activity patterns for large proportions of the population in most countries. Overweight and obesity are still emerging as major public health problems yet the comorbidities are very high, as the proportion of body fat in Asian adults was 5-6\% higher for a given body mass index (BMI) in the 1920s than in equivalent white adults in
Europe and the USA. Du and his co-authors ${ }^{31}$ show the Chinese shift towards an energy-dense diet, high levels of sedentarianism and increased obesity. These changes are still mainly found among adults and hypertension levels are very high. Diabetes and CVD are emerging as serious problems. China fits the East Asian pattern where very high levels of hypertension emerge first and diabetes and CVD are seen later.

India is at a much earlier stage of the transition and only the urban areas are greatly affected. Nonetheless, the burden of CVD is great and there is evidence of a large

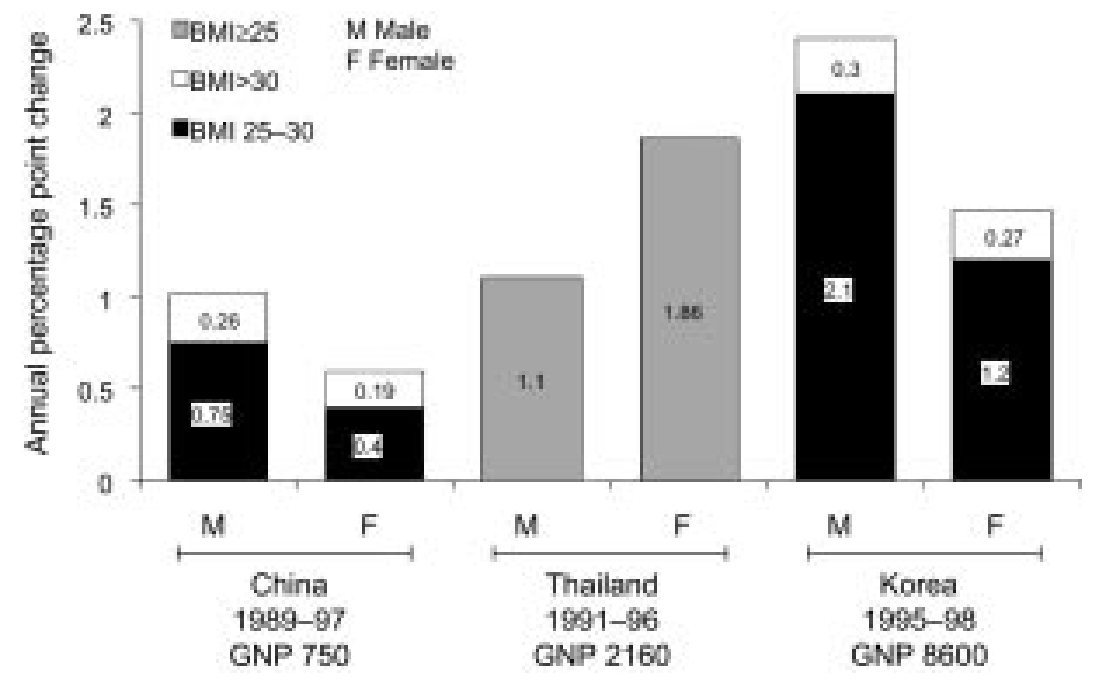

Fig. 10 Obesity trends among adults in Asia (the annual percentage point increase in prevalence). GNP - per capita gross national product (in 1998 US\$). Sources: Du et al. ${ }^{31}$; Kosulwat ${ }^{32}$ and Lee et al. ${ }^{34}$ 
increase in NR-NCDs in India. The absolute number of new diabetic cases in India is larger than in any other country of the world. Together, India and China comprise the majority of new cases of diabetes in the world. India's dietary pattern includes very high dairy and sugar consumption and there are marked increases in energy density of the diet, at both urban and rural levels.

Kosulwat $^{32}$ carefully documents the remarkable social and economic transitions Thailand has undergone. She shows how obesity even among children and adolescents is increasing dramatically and similar changes among adults are very rapid (Fig. 10). Consumption of animal products and energy from fat have increased markedly and carbohydrate intake has shifted downward as part of a marked change in the structure of the diet towards one dominated by animal products. At the same time, there is a positive increase in fruit and vegetable intake.

As Noor $^{33}$ shows, there are much fewer data for Malaysia so food balance and other data are used and less clarity is provided about the dynamic changes in the Malaysian diet and lifestyle. He points to one important dimension in Malaysia - very high levels of fast food intake and evidence of high overweight and obesity levels among males and females.

South Korea, the highest-income country represented in this supplement, provides a unique example of the good things a country can do to preserve the healthful elements of its cuisine ${ }^{34}$. A combination of large-scale training of housewives in preparing the traditional low-fat, highvegetable cuisine coupled with strong social marketing has led to very low fat and high vegetable intake levels. Obesity is considerably below that expected for a country with its high income level, as is the percentage of energy from fat. Among all of the countries represented in this meeting and others we know, South Korea has done the best job of preserving the healthful dimensions of its traditional cuisine.

The obesity patterns and trends are summarised in Figs $9^{31-37}$ and $10^{31,32,34}$ for countries from this region. Obesity and overweight levels are lower than those in many of the other regions and countries. However, the high levels of NR-NCDs in this region are caused by these changes in diet, activity and body composition, so the disease impact of the shifts towards a high energy-dense diet and sedentarianism and obesity are most important.

\section{What is unique about the experience in lower- and middle-income less-industrialised countries compared with the very-high-income industrialised countries?}

\section{Is the speed of change greater today?}

Is there anything about the great rapidity of change in diet, activity and body composition that matters? What does the high prevalence of the undernutrition-and-overweight combination in the same household mean in this context?
My paper attempts to summarise current knowledge on these topics ${ }^{38}$. While there is no study that clearly explores these points, extant data from Europe and the USA would lead us to believe that the rates of change in diet, activity and obesity in the developing world today are far beyond those experienced earlier by these countries. As the figures have shown, the increased percentage points in the prevalence of overweight and obesity per year are much higher than found in Europe and the US over the past several decades. In a very short time many low- and middle-income countries have attained rates of overweight and obesity greater than or equal to those of the USA and Western Europe.

\section{Is the biology different?}

There is limited but strong evidence that the biology is indeed different. Do we need different BMI cut-off points for sub-population groups and is this based on biological differences or just adiposity measurement that is missed with the use of BMI? That is, do we just have such imprecise measurement that this is the problem? Again there is evidence from a range of body composition and BMI-disease studies that would lead us to believe that the answer is yes. That is, Asians, Africans and Latin Americans are more likely than whites in the USA and Europe to have greater body fat and central fat for the same BMI and to have a higher likelihood of experiencing CVD outcomes of importance at lower BMI levels.

In addition, I note that there is the highly suggestive literature on issues related to foetal and infant insults. Termed the foetal origins or infant programming literature, this literature suggests that a rapid shift towards energy imbalance preceded by high levels of thin babies and infant stunting will have important long-term effects in increasing the probability that the subsequent energy imbalance leads to CVD and various conditions linked with CVD.

\section{How do we interpret the high levels of both undernutrition and overweight in the same bousebold and are there important programmatic issues related to this topic and that of managing undernutrition during this rapid transition?}

With the problems of undernutrition predominating, we are now facing this new shift in many countries. This brings up programme and policy concerns. One issue is the shift towards households with under- and overweight. How do we explain this? Doak ${ }^{39}$ shows it is a non-random systematic set of factors (higher income, urban residence) and other social factors that are related to this type of household.

The second is the issue of food and nutrition programme design. How do we get policy makers to focus on prevention of poor dietary and activity patterns and accelerated obesity? How do the politics of hunger interact with these new concerns? Are these problems of 
NR-NCD, etc. seen as the purview of treatment and not prevention, and how do we change that? Are there many examples where current programmes based on the needs of the hungry and undernourished are actually hurting the nutritional status of the recipients because they are focused on problems of undernutrition, but the programme recipients are becoming obese? Uauy and Kain ${ }^{40}$ show that we must be very careful in implementing feeding programmes for marginally undernourished children during advanced stages of this transition.

\section{Are there unique points about the CVD epidemic to consider?}

Reddy ${ }^{41}$ shows that the most globally pervasive change among these health transitions has been the rising burden of non-communicable diseases (NCDs). He shows how the rising burdens of CVD exemplify the high costs that unchecked epidemics of NCDs will impose on healthcare systems, and the adverse effects on development that would result from mid-life death and disability. His paper provides some sense of the temporal relationship between the various changes in the key obesity co-morbidities: hypertension, dislipidaemia, diabetes and CVD. In particular, he gives some sense that while the profile of CVD varies among the developing countries, there is a general progression from a large burden of rheumatic heart disease, as well as infectious and nutritional cardiomyopathies in the early stages to hypertension, then to haemorrhagic stroke and hypertensive heart disease, and finally these are largely replaced by thrombotic strokes and coronary heart disease. His paper also argues that the risk associated with obesity, poor diet and sedentarianism worsens as one shifts to the right on the distribution for each element. He argues that there is no clear cut-off beyond which risk emerges.

Vorster $^{42}$ shows how stroke has emerged as a major public health problem amongst black South Africans, possibly because of an increase in hypertension, obesity, smoking habit and hyperfibrinogenaemia during various stages of urbanisation. She also shows that black South Africans may be protected against ischaemic heart disease (IHD) because of favourable serum lipid profiles. Her paper focuses on the role of urbanisation and provides some sense of the importance of this factor in many countries. Her paper also poses issues that arise as we are attempting to understand the myriad of ways that different sub-populations are found to be more and less vulnerable to various shifts in diet, activity and body composition.

\section{Can we turn back the clock or modify the adverse dynamics? Programme and policy issues}

This section contains a series of papers focused on the early efforts in low- and moderate-income countries to prevent many of the most adverse dimensions of the rapid shift to the NR-NCD pattern. The general message is that a combination of national and local efforts focused on changes not only in the economic and physical environment, but also use of mass media and various settings (work, school, community), is needed to create the wide-scale changes needed.

Puska et $a l^{43}$ provide a clear example of how an integrated approach to dietary change can affect the structure of the diet and reduce NR-NCDs considerably. They focus on the need for intersectoral collaboration with one responsible national agency as the focal point. They then lay out how, in Finland, national price policy and food-labelling policies were combined with nutrition education programmes, with the enlistment of voluntary organisations, to tackle this effort. The authors discuss the need to involve industry at national and international level also. The paper shows how research and demonstration efforts also comprise important elements in the large-scale effort needed.

Matsudo and co-workers ${ }^{44}$ present some of the key elements used to launch a mass promotion of physical activity in São Paulo, Brazil. Termed the Agita São Paulo, it began as a multi-level, community-wide intervention designed to increase knowledge about the benefits and the level of physical activity in a mega-population of 34 million inhabitants of São Paulo State, Brazil. It is being expanded into a national effort slowly. Beginning with the main message that 30 minutes per day, on most days of the week, of moderate-intensity physical activity in one single or in multiple sessions is important, the programme encourages activity at home, leisure and in transport between locations. It focuses all education materials and efforts on a 'one-step-ahead' model. It has made widespread use of population mass activity Agita days, where millions walk, and a wide range of messages and approaches to reach all socio-economic classes as components. The Agita approach focuses on partnering with many different sectors to empower persons of all ages and classes. It is a new effort that started after the reduction of obesity presented in the paper of Monteiro et $a l .{ }^{16}$. It promises to be an important dimension of the Brazilian effort to improve diet and reduce sedentarianism.

Zhai et $a l .{ }^{45}$ and Coitinho et $a l .{ }^{46}$ provide two important overviews of China and Brazil, countries that have begun to address this topic. China began in the late 1980s to consider price policies and other food policies that might retard or arrest the rapid shift towards an energy-dense diet but did little else in the last decade. The Chinese Academies of Agricultural Sciences and Preventive Medicine (including as a key component the Institute of Nutrition and Food Hygiene) and the State Council met in one international meeting to review evidence in 1990 regarding the shift in structure of the Chinese diet and patterns of morbidity and mortality. Now they have begun to consider a wide-ranging set of activities in nutrition and other sectors to address the very rapid increase of NR-NCD 
seen in China. In the health sector, efforts related to reducing hypertension and diabetes are becoming more widespread, but there is limited work in the nutrition sector aside from the creation of dietary guidelines. This paper points to some unique strengths from past Chinese efforts and to an agenda for the next several decades.

In Brazil, a more co-ordinated and systematic effort is underway. The effort began more recently but has created a number of important legislative and regulatory policies, revised one very large school-feeding programme and done much to focus on the national policy environment. At the same time efforts at mass communication - directly via the mass media and through schools and food stores are underway. Furthermore, efforts at long-term capacity building have begun. The effort of Matsudo et al. ${ }^{44}$ noted above is a key component of this effort.

Doak $^{47}$ summarises some of the NR-NCD programme, policy and monitoring efforts underway in the countries represented by the Bellagio meeting. The focus was on large-scale efforts. As she shows, there are few of these. There were few exemplary national efforts. One was the national initiative in Thailand in public schools to promote a more healthful diet and more physical fitness and activity.

\section{The Bellagio Declaration and other final points}

This conference focused on the discussion of a topic that really has only come to the public attention in a serious way in the last decade. The group felt it was very important to create a consensus declaration that spoke to the essence of the discussions. At the end of the supplement we publish this declaration. This addresses how NR-NCDs are now the main causes of disability and death, not only globally but also in most developing countries. The critical focus was on prevention. The group unanimously felt that prevention is the only feasible approach to addressing this epidemic of nutrition-related chronic diseases. The cost of their treatment and management imposes an intolerable economic burden on developing countries. There is an urgent need for governments, in partnership with all relevant constituencies, to integrate strategies to promote healthful diets and regular physical activity throughout life into all relevant policies and programmes, including those designed to combat undernutrition.

The Bellagio conference and this supplement were supported by a number of important funding sources. First and foremost was the World Cancer Research Fund, which provided an important seed grant for this meeting. Second were the Rockefeller Foundation and the Bellagio Study and Conference Center. The Foundation provided funding for travel for persons from selected lower-income countries and also provided a unique and wonderful but isolated setting for the accommodations of all participants and spectacular accommodation. Third was important funding for publications and travel from the Carolina Population Center, University of North Carolina at Chapel Hill (UNC-CH), and two of my grants. We thank the Fogarty International Center (TW/HD00633) and the National Institutes of Health (NIH) (R01-HD38700) for added support.

A number of persons were most instrumental in organising and implementing the meeting. Foremost was my administrative assistant, Ms Frances Dancy, who handled all travel and logistics for the attendees. Mr Bill Shapbell edited and organised the papers in a most timely and excellent manner. Mr Tom Swasey edited graphics for the final publications. Several UNC-CH Doctoral candidates, Ms Soowon Kim, Ms Colleen Doak and Ms Samara Nielsen, provided invaluable assistance at various stages. Ms Doak is also thanked for helpful comments on this introduction. Carlos Monteiro came to Chapel Hill to assist in preparing the final agenda and handling many papers and other scientific issues. Geoffrey Cannon was a major force of encouragement and vision in the early stages. I thank all of these persons.

Of course, all of the participants, who are the first authors of all of the papers in this volume, were the key elements in this meeting and publication. Their interest, encouragement and active involvement were critical to the success of this activity.

For further information and access to publications and other materials from the Bellagio meeting, including slide presentations, go to the Nutrition Transition Program website: www.nutrans.org or www.nutritiontransition.org.

\section{Barry M Popkin}

Professor of Nutrition, Carolina Population Center, CB \# 8120 University Square, University of North Carolina at Chapel Hill, Chapel Hill, NC 27516-3997, USA

\section{References}

1 Omran AR. The epidemiologic transition: a theory of the epidemiology of population change. Milbank Q. 1971; 49: 509-38.

2 Olshansky SJ, Ault AB. The fourth stage of the epidemiologic transition: the age of delayed degenerative diseases. Milbank Q. 1986; 64: 355-90.

3 Truswell AS. Diet and nutrition of hunter-gathers. In: Health and Diseases in Tribal Societies. Ciba Foundation Symposium 149. Amsterdam: Elsevier, 1977; 213-26.

4 Harris DR. The prehistory of human subsistence: a speculative outline. In: Walcher DN, Kretchmer N, eds. Food, Nutrition and Evolution: Food as an Environmental Factor in the Genesis of Human Variability. New York: Masson, 1981; 15-37.

5 Eaton SB, Shostak M, Konner M. The Paleolithic Prescription: A Program of Diet and Exercise and a Design for Living. New York: Harper \& Row, 1988.

6 Eaton SB, Konner M. Paleolithic nutrition: a consideration on its nature and current implications. N. Engl. J. Med. 1985; 312: $283-9$.

7 Vargas LA. Old and new transitions and nutrition in Mexico. 
In: Swedlund AC, Armelagos GJ, eds. Disease in Populations in Transition. Westport, CT: Greenwood, 1990.

8 Gordon KD. Evolutionary perspectives on human diet. In: Johnson FE, ed. Nutritional Anthropology. New York: Liss, 1987; 3-41.

9 Newman L, Kates RW, Matthews R, Millman S. Hunger in History. Cambridge, MA: Basil Blackwell Ltd, 1990.

10 Milio N. Nutrition Policy for Food-Rich Countries: A Strategic Analysis. Baltimore, MD: The Johns Hopkins University Press, 1990.

11 Popkin BM, Haines PS, Reidy KC. Food consumption of the U.S. women: patterns and determinants between 1977 and 1985. Am. J. Clin. Nutr. 1989; 49: 1307-19.

12 Popkin BM, Haines PS, Patterson R. Dietary changes among older Americans 1977-87. Am. J. Clin. Nutr. 1992; 55: 823-30.

13 Manton KG, Soldo BJ. Dynamics of health changes in the oldest old: new perspective and evidence. Health and Society 1985; 63: 206-85.

14 Crimmins EM, Saito Y, Ingegneri D. Changes in life expectancy and disability-free life expectancy in the United States. Popul. Dev. Rev. 1989; 15: 235-67.

15 Albala C, Vio F, Kain J, Uauy R. Nutrition transition in Chile: determinants and consequences. Public Health Nutr. 2002; 5: $123-8$.

16 Monteiro CA, Conde WL, Popkin BM. Is obesity replacing or adding to undernutrition? Evidence from different social classes in Brazil. Public Health Nutr. 2002; 5: 105-12.

17 Rivera JA, Barquera S, Campirano F, Campos I, Safdie M, Tovar V. Epidemiological and nutritional transition in Mexico: rapid increase of non-communicable chronic diseases and obesity. Public Health Nutr. 2002; 5: 113-22.

18 Rodríguez-Ojea A, Jiménez S, Berdasco A, Esquivel M. The nutrition transition in Cuba in the nineties: an overview. Public Health Nutr. 2002; 5: 129-33.

19 Galal OM. The nutrition transition in Egypt: obesity, undernutrition and the food consumption context. Public Health Nutr. 2002; 5: 141-8.

20 Benjelloun S. Nutritional transition in Morocco. Public Health Nutr. 2002; 5: 135-40.

21 Ghassemi H, Harrison G, Mohammad K, Balaa ALN. An accelerated nutrition transition in Iran. Public Health Nutr. 2002; 5: 149-55.

22 Al-Isa AN. Prevalence of obesity among adult Kuwaitis: a crosssectional study. Int. J. Obes. 1995; 19: 431-3.

23 Al-Isa AN. Changes in body mass index (BMI) and prevalence of obesity among Kuwaitis 1980-1994. Int. J. Obes. 1997; 21: 1093-9.

24 Al-Nuaim AR, Al-Rubeaan K, Al-Mazrou Y, Al-Attas O, AlDaghari N, Khoja T. High prevalence of overweight and obesity in Saudi Arabia. Int. J. Obes. 1996; 20: 547-52.

25 Al-Mannai A, Dickerson JWT, Morgan JB, Khalfan H. Obesity in Bahraini adults. J. Roy. Soc. Health 1996; 116: 30-40.

26 Shetty PS, James WPT. BMI distribution in developed and developing countries. In: Body Mass Index: A Measure of Chronic Energy Deficiency in Adults. FAO Food and Nutrition Papers No. 56. Rome: Food and Agriculture Organisation of the United Nations, 1994; Chapter 7.

27 Ajlouni K, Jaddou H, Batieha A. Obesity in Jordan. Int. J. Obes. 1998; 22: 624-8.

28 Hodge AM, Dowse GK, Gareeboo H, Tuomilehto J, Alberti $\mathrm{KG}$, Zimmet PZ. Incidence, increasing prevalence, and predictors of change in obesity and fat distribution over 5 years in the rapidly developing population of Mauritius. Int. J. Obes. 1996; 20: 137-46.

29 Bourne LT, Lambert EV, Steyn K. Where does the black population of South Africa stand on the nutrition transition? Public Health Nutr. 2002; 5: 157-62.

30 Maletnlema TN. A Tanzanian perspective on the nutrition transition and its implications for health. Public Health Nutr. 2002; 5: 163-8.

31 Du S, Lu B, Zhai F, Popkin BM. A new stage of the nutrition transition in China. Public Health Nutr. 2002; 5: 169-74.

32 Kosulwat V. The nutrition and health transition in Thailand. Public Health Nutr. 2002; 5: 183-9.

33 Noor MI. The nutrition and health transition in Malaysia. Public Health Nutr. 2002; 5: 191-5.

34 Lee M-J, Popkin BM, Kim S. The unique aspects of the nutrition transition in South Korea: the retention of healthful elements in their traditional diet. Public Health Nutr. 2002; 5: 197-203.

35 Shetty PS. Nutrition transition in India. Public Health Nutr. 2002; 5: 175-82.

36 Solon FS. Nutrition Related Chronic Diseases in the Philippines. Nutrition Center of the Philippines Report Series, Vol. 2, No. 1. Makati City, Philippines: Nutrition Center of the Philippines, 1997.

37 Popkin BM, Kohlmeier L, Zohoori N, Baturin A, Martinchik A, Deev A. Nutritional risk factors in the former Soviet Union. In: Bobadilla J-L, Costello C, eds. Premature Death in the New Independent States. Washington, DC: Academy Press, 1997; 314-34.

38 Popkin BM. The shift in stages of the nutrition transition in the developing world differs from past experiences! Public Health Nutr. 2002; 5: 205-14.

39 Doak C. Large scale interventions and programmes related to chronic disease: examples from 14 countries. Public Health Nutr. 2002; 5: 215-21.

40 Uauy R, Kain J. The epidemiological transition: need to incorporate obesity prevention into nutrition programmes. Public Health Nutr. 2002; 5: 223-9.

41 Reddy KS. Cardiovascular diseases in the developing countries: dimensions, determinants, dynamics, and directions for public health action. Public Health Nutr. 2002; 5: $231-7$.

42 Vorster HH. The emergence of cardiovascular disease during urbanisation of Africans. Public Health Nutr. 2002; 5: 23943.

43 Puska P, Pietinen P, Uusitalo U. Influencing public nutrition for non-communicable disease prevention: from community intervention to national programme - experiences from Finland. Public Health Nutr. 2002; 5: 245-51.

44 Matsudo V, Matsudo S, Andrade D, Araujo T, Andrade E, de Oliveria LC, Braggion G. Promotion of physical activity in a developing country: the Agita Sao Paulo experience. Public Health Nutr. 2002; 5: 253-61.

45 Zhai F, Fu D, Du S, Ge K, Chen C, Popkin BM. What is China doing in policy-making to push back the negative aspects of the nutrition transition? Public Health Nutr. 2002; 5: 269-73.

46 Cointinho D, Monteiro CA, Popkin BM. What Brazil is doing to promote healthy diets and active lifestyles. Public Health Nutr. 2002; 5: 263-7.

47 Doak C, Adair LS, Bentley ME, Zhai F, Popkin BM. The underweight/overweight household: an exploration of household sociodemographic and dietary factors in China. Public Health Nutr. 2002; 5: 279-80. 